\title{
HVMANITAS
}

\section{Eros e identidade nas Suplicantes de Ésquilo}

\author{
Autor(es): $\quad$ Fialho, Maria do Céu
}

Publicado por: Imprensa da Universidade de Coimbra

URL persistente:

URl:http://hdl.handle.net/10316.2/27382

DOI:

DOI:http://dx.doi.org/10.14195/2183-1718_64_3

Accessed : $\quad$ 26-Apr-2023 10:42:06

A navegação consulta e descarregamento dos títulos inseridos nas Bibliotecas Digitais UC Digitalis, UC Pombalina e UC Impactum, pressupõem a aceitação plena e sem reservas dos Termos e Condições de Uso destas Bibliotecas Digitais, disponíveis em https://digitalis.uc.pt/pt-pt/termos.

Conforme exposto nos referidos Termos e Condições de Uso, o descarregamento de títulos de acesso restrito requer uma licença válida de autorização devendo o utilizador aceder ao(s) documento(s) a partir de um endereço de IP da instituição detentora da supramencionada licença.

Ao utilizador é apenas permitido o descarregamento para uso pessoal, pelo que o emprego do(s) título(s) descarregado(s) para outro fim, designadamente comercial, carece de autorização do respetivo autor ou editor da obra.

Na medida em que todas as obras da UC Digitalis se encontram protegidas pelo Código do Direito de Autor e Direitos Conexos e demais legislação aplicável, toda a cópia, parcial ou total, deste documento, nos casos em que é legalmente admitida, deverá conter ou fazer-se acompanhar por este aviso. 
humanitas

\section{Vol. LXIV \\ 2012}

IMPRENSA DA UNIVERSIDADE DE COIMBRA

COIMBRA UNIVERSITY PRESS 


\title{
EROS E IDENTIDADE NAS SUPLICANTES DE ÉSQUILO
}

\author{
Maria do Céu Fialho \\ Universidade de Coimbra \\ Centro de Estudos Clássicos e Humanísticos
}

\section{Resumo:}

Este artigo analisa as causas e elementos constitutivos das tensões trágicas, sobretudo as razões do repúdio violento das Danaides pelos seus perseguidores, os filhos de Egipto. O público identifica o impulso dos Egípcios como uma manifestação típica do poder de Eros, tal como a poesia grega, desde Homero, canta a força selvagem de Afrodite-Eros. Mas as vítimas de Eros, num contexto grego e civilizado, submetem-se ao seu poder e lamentam a sua sorte - mas nunca tentam dominar pela força o estímulo das suas afeições, o seu amado. Os Egípcios, ao identificarem a sua paixão com o direito de subjugar pela violência as mulheres que desejam, não têm em conta nem a vontade das Danaides nem do seu pai, Dânao, senhor da sua própria casa. Não respeitam nem as instituições, nem a natureza, porque o amor e o modo de conquistar a atenção de uma pessoa amada implica um processo particular de abordagem e sedução. O comportamento das Danaides, ao repudiarem, radicalmente, o casamento, é hibrístico; por seu lado o comportamento dos Egípcios pertence, como é óbvio, a um padrão não grego - e, por isso, são apelidados pelas Danaides de hybristai, como sinónimo de bárbaros. Ao mesmo tempo que as Danaides se afirmam como gregas, não se dão conta da sua ascendência comum, grega / divina.

Palavras-chave: Suplicantes de Ésquilo, Eros, casamento, identidade, Grego / Bárbaro.

\section{Abstract:}

This paper analyses the causes and constitutive elements of the tragic tensions, mainly the reasons for Danaids' violent repudiation of their suitors, the sons of 
Egypt. The audience identifies the Egyptians' impulse as a typical manifestation of the power of Eros in the way that Greek poetry, since Homer, sings of the wild force of Aphrodite-Eros. But Eros' victims, in a Greek, civilized context, suffer under his power and complain about their fortune - they never try to dominate by force the object of their affections, the loved one. The Egyptians, by identifying their passion with the right to dominate the desired women by violence, do not take into account either the Danaids' will or the will of their father, Danaos, lord of his own house. They neither respect institutions nor Nature, because love and the way to win the attention of the beloved person implies a particular procedure of requesting and seducing. The Danaids' behaviour, as far as they reject marriage at all, is hybristic; the Egyptians' behaviour belongs to an obvious non-Greek pattern - so are they characterized by the Danaids, who call them hybristai, in this context almost a synonym of Barbarian. Simultaneously the Danaids assert themselves as Greek, aware of their common Greek/divine ascendancy.

Key words: Aeschylus' Suppliants, Eros, marriage, identity, Greek/Barbarian.

Até à descoberta do papiro Ox. 2256.3 as Suplicantes, primeira obra de uma trilogia perdida, a das Danaides, foi considerada como a mais antiga sobrevivente das tragédias compostas por Ésquilo. Esta cronologia relativa baseou-se, entre outros critérios, no da função e predominância do Coro na acção. A peça abre, precisamente, num clima de profunda perturbação emocional, sublinhada cenicamente pelo movimento agitado e pelo ritmo e a natureza de um longo canto que o Coro, constituído pelas filhas de Dânao, entoa, enquanto busca alcançar um termo para a sua fuga, desde longínquas paragens, até ao altar do deus, em Argos, a cuja sombra se acolhe, em súplica: Zeus Hikesios. E porque elege o Coro a cidade de Argos? Fá-lo, tomando como motivo uma ancestral memória que o relaciona com aquela pólis. Aquela é a terra natal da sua antepassada Ío, que de Zeus deu à luz, após uma antiga história de eros e violência, perseguida pelos ciúmes de Hera, no sentido inverso àquele que percorreram as donzelas perseguidas, suas descendentes.

E de que fogem estas mulheres? Das núpcias a que as querem conduzir, à força, os filhos de Egipto, seus primos, também descendentes da mesma cepa - de Zeus e Io.

Já muito se especulou e escreveu sobre esta peça, e, por vezes, sobre ela se projectam conceitos e preconceitos que não são helénicos. É o caso da questão do parentesco entre as Danaides e os filhos de Egipto. Se atendermos à mitologia grega, dois exemplos ressaltam, à partida: o do par 
Antígona e Hémon ou o de Orestes e Hermíone, que nos permitem perceber que o casamento entre primos (e primos direitos, note-se) era aceite como normal. $\mathrm{E}$ o que na mitologia se cristaliza corresponde à realidade social e ao juridicamente preceituado.

Já o legislador Sólon havia salvaguardado a possibilidade legal até do casamento entre irmãos, ainda que com restrições: desde que se tratasse de filhos do mesmo pai, mas de mães diferentes ${ }^{1}$. Por outro lado, em caso de morte do senhor da casa (kyrios), as filhas órfãs passavam a estar debaixo da tutela de um epikleros, o parente masculino mais próximo do progenitor ${ }^{2}$, que providenciaria não só o sustento destas como o seu matrimónio dentro da família, de modo a que se mantivesse salvaguardada a continuidade do oikos e se conservasse intacto o seu património.

As núpcias contra a themis (v.38) são-no, pois, por motivos diversos que não o da consanguinidade. Caso se concretizasse, tratar-se-ia de um casamento não desejado, nem pelas jovens nem por seu pai, mas imposto por seus primos. É por esse motivo que fogem as filhas de Dânao. A vontade paterna pesava determinantemente sobre o destino das filhas, e o das Danaides não constitui excepção: Dânao é o seu pater e o seu boularchos kai stasiarchos (v. 11-12), pese embora a sua vontade interpretar a disposição e determinação de suas filhas ${ }^{3}$.

Estas jovens sentem-se ameaçadas pela perseguição que sofrem por parte de seus primos que, segundo elas chegam a afirmar, pretendem impor-lhes uma união à força. De resto, o termo bia e seus cognatos, como manifestação da violência desmedida do impulso erótico dos filhos de Egipto, de que as Danaides se sentem vítimas, apresenta uma excepcional

$1 \quad$ F 47 R (Fílon, De spec. leg.3.22). Vide i. a. M. Gagarin (1986) Early Greek law, Berkeley 1986: 67, D. Leão(2001) Sólon. Ética e política, Lisboa: 365. Cf. E. Crespo (2008), "Léxico y temas en Las Suplicantes de Esquilo", Teatro y sociedad en la Antigüedad Clásica, J. V. Bañuls-F. De Martino-C. Morenilla (eds.), Bari: 121-122.

2 Sobre a ankhisteia e o epiclerato, vide i. a. S.C. Todd (1993) The shape of Athenian law, Oxford 1993, 216-219; 228-231, I. Calero Secall(2004) "El privilegio de masculinidad y los derechos femeninos en las transmisiones patrimoniales de la Grecia Clásica": D. Leão, L. Rossetti, M. C. Fialho (eds.), Nomos. Derecho y sociedade $n$ la Antiguedad Clásica, C oimbra-Madrid165 sqq.

3 Ainda assim, é justa a observação de A. F. Garvie (2006) Aeschylus' Supplices. Play and trilogy, Bristol,2.ed, 129: "Aeschylus has chosen to give to the girls the task of negotiation with the Argive king. So too they must face alone the Egiptian herald. The agon is to be between a bando f weak and helpless girls and the strong and menacing Egipcian male (or males)". 
frequência nesta tragédia ${ }^{4}$, e é com a perspectiva iminente dessa mesma violência que a peça encerra, num final aberto que prepara o espectador para a peça subsequente.

A bela imagem que de si mesmas dão as jovens, ao longo do párodo, é extremamente expressiva sobre o modo como vivem a sua situação e a ameaça que sobre elas pesa: são como o rouxinol, de voz lamentosa, perseguido pelo falcão (vv. 61-62), imagem que Dânao voltará a utilizar, com outra variante ornitológica, no v. 223: as jovens são como um bando de pombas perseguido pelo falcão ${ }^{5}$.

O impulso erótico desmedido converte os pretendentes em predadores que perseguem a sua presa. Assim se encontram já transgredidos os limites que determinam o comportamento social próprio de um contexto de mundo civilizado. É que, ainda que tais impulsos sejam manifestação da própria vitalidade da natureza, numa sociedade civilizada eles são enquadrados num contexto de regras de convivência social, política e institucional. É precisamente no modo como encaram e lidam com essa transgressão que as Danaides e seu pai, ainda que se reconheçam como sendo da mesma raça que a dos filhos de Egipto, sentem que radica a diferença de identidade entre uns e outros - estes são Bárbaros, elas e Dânao Gregos, apesar de tudo o que parece diferenciá-las dos habituais padrões de vestuário e de pureza de linguagem, mais precisamente, de pronúncia: karbana ...audan, v. 128 , em relação a $\operatorname{Argos}^{6}$.

Sem dúvida que, como é tão peculiar à estratégia dramatúrgica de Ésquilo, por detrás da bela imagem do rouxinol e do falcão, se evoca a historia de Tereu e Procne, já que o canto de lamento da avezinha é referido

4 Vv. 96, 430, 576, 798, 812, 821, 831, 850, 863 (bis), 943, 1068.

5 As pombas aqui referidas são as peleiai ('columbae liviae'), pombas bravas, que habitam os rochedos, não as domésticas (peristerai). E. Petrounias (1976) Funktion und Thematik der Bilder bei Aischylos, Göttingen, 177, comenta:"Sowohl äusserlich als auch innerlich entsprechen die Danaiden den Felsentauben. Auch sie sind schwärzlich (...279 f., ...71). Die Felsentauben kommen an den felsigen Küsten Griechenlands scharenweise vor, wie die Danaiden an der argivischen Küste gekommen sind (1 ff., 223 u. a.). Roh und hartnäckig sind die Mädchen; man kann sie nicht züchten. Das Bild passt auch zu den “Nicht-Griechinnen” Danaiden.”...”Alle kleinere Vögel werden wie die Danaiden in Angst versetzt und stossen schrilles Geschrei aus, wenn sie einen Habicht wahrnehmen, der ihnen Tod bringt...". Petrounias sublinha o exemplo épico de Il. 17. 755; 22. 139-142.

6 Sobre a multiplicidade de aspectos diferenciadores do comportamento, mentalidade e aspecto das Danaides, quando comparadas com o padrão grego, vide A. P. Q. Sottomayor (1968), Ésquilo. As Suplicantes. Prefácio, introd. trad. notas, Coimbra, 9-15. 
através da perífrase 'a voz da esposa de Tereu' (v. 61). Assim se remete para uma história de impulso erótico descontrolado por parte de Tereu, de violência e vingança descomedidamente sangrenta por parte dos elementos femininos da casa, que é aniquilada com o sacrifício, por vingaça, da sua descendência. A fragilidade do rouxinol e a fragilidade das Danaides, associada, remete para una violência pretérita, no mito evocado, e sugere, talvez, a violência futura, no mito dramatizado.

No que diz respeito à identidade helénica reiterada, por parte do Coro, muito haveria a dizer sobre o que a caracteriza e o que a dilui - note-se o modo como as jovens se dirigem a Pelasgo, no pressuposto de que o seu poder é absoluto, autocrático, sem vínculo à voz da sua pólis e que implica concepções de poder orientais e não gregas ${ }^{7}$; note-se a manifestação excessiva do pathos das filhas de Dânao, que ameaçam pôr fim às suas vidas junto aos altares dos Olímpicos, caso não vejam atendidas as suas súplicas, o que representaria um gesto contrário ao princípio do 'nada em excesso' e que, além do mais, contaminaria espaços sagrados.

Pode, pois, entender-se que esta tragédia $-\mathrm{e}$, consequentemente, a trilogia - se inicia sob o signo da ambiguidade. As Suplicantes afirmam-se gregas, mas posicionam-se, em boa verdade, dentro dessa área esbatida das fronteiras da identidade, quer pelos seus gestos, pelo seu modo de pensar, quer, em parte, pelo seu vestuário, que provocará a estranheza de Pelasgo, quer ainda pelo acento bárbaro do seu grego ${ }^{8}$.

As Danaides fogem à violência do jugo de um casamento imposto como se fora uma forma de escravatura. São acompanhadas por seu pai, que tenta preservá-las desse jugo e que é quem, verdadeiramente, inspirou esta insurreição. Mas de que tenta, realmente, preservá-las? De que fogem as filhas de Dânao? Somente de um casamento imposto? De noivos que lhes repugna aceitar? Que significa, verdadeiramente, a expressão autogenei phyxanoriai (v. 9) com que percorrem os seus caminhos e que seu pai

7 J. V. Bañuls Oller - P. Crespo Alcalá (2002) "Las Suplicantes de Esquilo y el héroe trágico", Das Tragische, C. Morenilla-B. Zimmermann (eds.), Stuttgart, 61 sqq. e L. G. Mitchell (2006) "Greeks, Barbarians and Aeschylus' Suppliants" G\&R, 53, 205-223.

8 Sobre o esbater das fronteiras da identidade, resultante da mobilidade, e a sua problematização, subjacente a Suplicantes, vide M. C. Fialho (2005) "Representações de identidade e alteridade em Ésquilo", M. C. Fialho-M. F. Silva- M. H. da Rocha Pereira (eds.), Génese e consolidação da ideia de Europa. Vol. I: de Homero ao fim da Época Clássica, Coimbra, 86-92. 
sanciona? Não se trata apenas de uma "fuga a homens da mesma raça", como certamente se pôde já perceber.

Voltarei a esta questão, que deixo em suspenso, para me concentrar agora na do comportamento dos Egípcios, que o espectador não observa, apenas dele toma conhecimento pelo relato que dele é feito pelas Danaides. Parece marcado pela asebeia, pela ofensa à themis, porque atenta contra a própria instituição do matrimónio como acto decorrente do acordo entre duas casas - acto que vem, desse modo, assegurar a própria estabilidade social e continuidade da comunidade. Apesar disso, o espectador reconhece a natureza da força que impele os Egípcios - trata-se da força de eros, poder universal ao qual nada pode escapar e que determina uma dinâmica cósmica, como a própria Afrodite acabará por declará-lo na última das peças da trilogia, no famoso frg. 44 Radt.

Esse eros que leva o poeta grego a celebrá-lo, como observa Lesky ${ }^{9}$, nada tem de amor aprazível, senão de força brutal, desestabilizadora da existência, que faz sofrer e que arrebata ao homem a sua própria segurança, fazendo com que se sinta outro, estranho a si mesmo. A brutalidade e o carácter inesperado de tais ataques levam o eu lírico, na poesia grega arcaica, a considerar eros, entre outras coisas, como tempestade ${ }^{10}$, pugilista $^{11}$, machado de lenhador ${ }^{12}$, fogo ${ }^{13}$, caçador que persegue a sua presa ${ }^{14}$, doença, loucura ${ }^{15}$, feitiço ${ }^{16}$, perigo de morte ${ }^{17}$. Sem dúvida, na tradição lírica grega essa violência chega a constituir una experiência da vítima directa dos ataques de eros ao ser colocada frente àquele ou àquela que funciona como estímulo erótico e que paira, na maior parte das ocasiões, inacessível e

9 A. Lesky(1976), Vom Eros der Hellenen, Göttingen, 41-43, 47 et passim.

10 Safo, frg. $2 P L F$.

11 Anacreonte, frg. 394PMG.

12 Anacreonte, frg.413PMG.

13 Safo, frg. 48PLF.

14 Íbico, frg. 285PMG.

15 E. g. Íbico, frg. $286 P M G$, Anacreonte, frgs. 359, 388, 398, $428 P M G$,

16 Na épica, vide e. g. Il. 14. 214: a faixa de Afrodite, contém, na sua textura e bordados, todos os thelkteria para a atracção amorosa. A súplica de Safo a Afrodite, que estrutura a ode do frg. 1PLF, apresenta em vv. 21-24 uma formulação típica da magia erótica( vide Ch. A. Faraone (1999), Ancient Greek love magic, Cambridge Massachusets London, 136-137. Íbico, por sua vez, fala do efeito encantatório dos kelemasi pantodapois de Eros, frg.285PMG, 3 (cf. E. Tr. 893 sobre o efeito encantatório da beleza de Helena).

17 Safo, frg. 95 PLF. 
alheio ao efeito que provoca. É com esse ataque de eros tyrannos $^{18}$ que se debate a voz lírica da vítima ${ }^{19}$.

Embora a imagem do jugo esteja presente na expressão da ligação amorosa (constitui um Leitmotiv em Anacreonte), a submissão a este, por parte da jovem que, outrora admetos parthenos, perde a virgindade no casamento, tem outra dimensão - a da sujeição institucional de quem passa do âmbito de Ártemis, do estádio da natureza não frequentada, ao da integração no contexto de um novo oikos, nele investida de funções, na sua qualidade de esposa ${ }^{20}$, damar . Esta transformação ocorre na sequência do consenso entre famílias, com o consentimento do kyrios da família de origem da jovem - o seu pai- e, possivelmente, com a anuência e simpatia desta. Para isso, a força da persuasão que harmoniza as partes e as aproxima ou as afasta é determinante. Existe, nesse jogo de aproximação determinado por eros (seja eros a força do amor e do prazer, ou manifeste-se ele como força tendente a perpetuar gerações), uma dimensão de ritual de persuasão até à cedência e entrega, embora esta, no seu ponto culminante, implique sempre a violência da fusão, da quebra momentânea da individualidade, da possibilidade futura da fertilidade até ao parto, para a mulher, que representa dor e violência física. $\mathrm{O}$ acto de cortejar, como já o notaram Winnington-Ingram e Beck ${ }^{21}$, representa una forma de exercício da persuasão.

Indubitavelmente os filhos de Egipto, dominados pela brutalidade do acicate erótico, de "pensamentos loucos, de um aguilhão irresistível" (dianoian mainolin/kentron ... aphykton, vv. 107-108), dão livre curso a essa violência, exercendo-a sobre o objeto dos seus desejos. O modo como o Coro descreve a sintomatologia dos Egípcios evoca a antiga loucura de Ío, atormentada pelo aguilhão do moscardo, instigado pelos ciúmes de Hera

18 Cf. E. Hipp. 538.

19 C. Calame,(1999), The poetics of eros in Ancient Greece (trad, ingl. J. Lloyd), Princeton, 19-23, realça a natureza do impulso erótico como reacção a um estímulo exterior, accionado por eros. Tal estímulo concentra-se, essencialmente, no olhar do outro, do amado, seja por efeito do brilho dos seus olhos, seja pela sua mera visibilidade: "It is clearly through sight that the recipient perceives the Eros emanating from the one who is desirable ...This state of erotic desire, which is aroused externally, is naturally fixed, in response, upon na object outside itself.”(p.21). Vide também M. C. Fialho (2009), “ A sexualidade na poesia grega" in: J. A. Ramos, M. C. Fialho, N. S. Rodrigues ((coords.), A sexualidade no Mundo Antigo, Lisboa, 253-261.

20 C. Calame 1999: 122-123.

21 R. P. Winnington-Ingram (1961) "The Danaid Trilogy of Aeschylus" JHS, 81, 151-152 y R. H. Beck (1975) Aeschylus: playwrhight educator, The Hague, 143-144. 
(mainomena ponois atimois odynais te kentrodaletesin thyias Heras, vv. 562-564).

Os Egípcios querem, sem mais, possuir as noivas que os não querem. Não há ritual de persuasão, nem do pai nem das filhas, nem sequer o de cortejá-las, numa tentativa de despertar o efeito de magia de eros. E esse é um procedimento natural até nas espécies de irracionais.

Nos Egípcios o desejo erótico desperta a fúria do prazer e da posse - contrariados estes, o caminho alternativo é o da conquista pela guerra, em que o exército vencedor arranca das suas casas as cativas de guerra e as arrasta até aos leitos onde servirão como objectos de prazer. Este universo em desordem e transgressão, que encontra expressão em palavras brutais e num grego que está longe de ser fluente - o do Mensageiro - evoca os medos do Coro das Mulheres de Tebas em Sete contra Tebas, tragédia de fecho da Trilogia Tebana, representada no ano de 467a.C., com toda a probabilidade quatro anos antes da trilogia das Danaides, quando aquelas imaginam a sua sorte, no caso de a cidade de Tebas vir a ser invadida pelo inimigo vencedor ${ }^{22}$.

Se os Egípcios são, afinal, tão argivos quanto as suas noivas fugidas, já que a ascendência dos dois grupos é a mesma, percebe-se o que faz deles bárbaros. Estes traços são sublinhados por outras referências, dadas por parte das jovens e de Dânao, com o objectivo opôr e de distanciar identidades: ao que foi dito combina Dânao e as suas filhas a alusão a hábitos diferenciados e ao culto a deuses diferentes - o que lhes dá margem a carregarem as cores do retrato dos primos como hybristai: hybristen Aigyptiogene (v. 394) ${ }^{23}$.

É a esta ameaça que o rei Pelasgo e Argos são sensíveis, ao acolherem as Suplicantes que se puseram sob a protecção de Zeus Hikesios - mesmo tendo consciência do perigo iminente que o seu gesto de protecção pode representar.

Contudo, esta situação singular tem uma contrapartida no universo feminino. De tais noivos, hostis a qualquer lei religiosa, social, natural, fogem as Danaides, numa reacção compreensível e, à primeira vista, natural. Os motivos da sua fuga esbatem-se em ambiguidade, precisamente pelos argumentos que vão apresentando. De facto, sobre a expressão autogenei

22 Cf. E. Crespo 2008: 20. A. H. Sommerstein, por seu turno, propõe 461 a. C como data da representação (apud Crespo p.20, n.4)

23 Vide M. C. Fialho 2005:.89. 
phyxanoriai (v. 9) irão surgindo explanações ${ }^{24}$, no diálogo lírico-epirremático entre Pelasgo e o Coro, como, por exemplo, nos versos 392-393 cantados pelas jovens: "que nunca eu venha a cair sob o poder dos machos". Mais expressivos ainda são os versos cantados sob o efeito do terror, quando o Mensageiro dos Egípcios já está em cena (vv. 854-857): “Que eu jamais veja de novo as águas fecundantes em que colhe alimento e vigor o sangue, fonte da vida".

Finalmente, o Coro suplica à casta Ártemis protecção contra qualquer casamento (gamos) que o coloque sob a acção de Afrodite (vv. 10311034) - a deusa que o Coro vê como amante de Ares sangrento, portanto inseparável da guerra e da violência (vv. 663-665).

$\mathrm{O}$ coro das servas tem como função minimizar o repúdio radical. Em boa verdade, é, em última instância, do casamento e da sua função procriadora, considerados como uma submissão e violência, aquilo de que foge o Coro. Dois âmbitos do universo se colocam, assim, em profunda tensão e dissonância - o feminino e o masculino.

A violência gera a violência. Dânao, que inspira e instiga a posição das Danaides, acabará por persuadi-las a executarem os seus noivos na própria noite de núpcias, quando estas são já inevitáveis. Perdeu-se a segunda e a terceira peça da trilogia. Provavelmente, na segunda teriam lugar as hostilidades que se anunciam no final das Suplicantes, com a derrota da cidade e a la morte do seu rei. As Danaides serão, de qualquer modo, entregues aos Egípcios e o ancião Dânao, então rei de Argos e condutor das negociações, induzirá as suas filhas nesse plano sangrento. Da protecção anteriormente conseguida sob a alçada de Zeus Hikesios o grupo passa, com as núpcias sangrentas, a uma grave ofensa a Zeus Xenios.

Somente Linceu escapará à chacina, libertado da morte por Hipermnestra. O destino dos Egípcios deveria ter-se consumado na obra homónima. Entre Linceu e Hipermnestra a força de himeros fará com que esta salve o seu noivo, embora desobedecendo a seu pai, de acordo com a profecia feita por Prometeu a Ío ( $P V 865$ ss). Este passo resume a acção desta trilogia, utilizando, inclusivamente, a imagem das pombas e do falcão (v. 857). Linceu deverá ter respeitado a virgindade de Hipermnestra e assumido o

24 A. F. Garvie 2006: 72 reconhece a intencional ambiguidade da expressão no seu contexto. Vide op. cit. pp. 215 sqq. Em que o prestigiado helenista apresenta uma perspectiva de conjunto das principais perspectivas, na investigação, sobre este passo e sobre a sua relevância para a interpretação global da peça. 
comportamento natural do pretendente que corteja, despertando, com isso, o himeros da donzela. Pausânias alude à antiga tradição de um santuário dedicado por Hipermnestra a Ártemis Peitho e de uma estatueta votiva a Afrodite Nikephoros (Paus. 2.19.6; 21.1).

O par será reabilitado no final da trilogia onde, com toda a probabilidade, teria lugar o julgamento e Hipermnestra seria defendida por Afrodite ${ }^{25}$. A universal valência do poder da deusa assegura a perpetuação da vida no cosmos e o natural ciclo da vida no contexto da pólis e das suas instituições.

Encontramo-nos no plano da mera conjectura, mas, com toda a probabilidade, e tendo em conta a cosmovisão esquiliana, através da reabilitação de Hipermnestra chegar-se-ia à reabilitação das restantes Danaides sanguinárias, apaziguadas perante uma instituição que haviam repudiado e perante a qual terão que ceder ou, pelo menos, terão que prestar-lhe reconhecimento.

Para além da tensão entre o masculino e o feminino, cuja presença é identificável noutras tragédias de Ésquilo, o espectador das Suplicantes tem, perante os seus olhos, a dramatização de um mythos que apresenta e avalia a tensão entre esferas de influência num universo em que a mulher tem que transferir-se de uma para a outra, a fim de ficar assim assegurada a estabilidade da comunidade e da sua perpetuação: a esfera do poder paternal e a do oikos que a espera, no qual se integrará como esposa e como mãe. Esta avaliação do papel da mulher no oikos, e da necessária conciliação entre oikoi, supõe o papel determinante de Eros - não de um eros salvagem, de posse e destruição, senão de um eros que dá força à comunicação e concatenação mulher-homem.

Toda a tragédia é política. A proximidade entre Argos e Atenas, naquela época, constituia um facto, e isso explica o motivo por que o rei e os habitantes da pólis estavam representados como ideais. Mas, acima de tudo, é essencialmente a importância da dimensão política do oikos que está em jogo. Na sua construção devem ser respeitados os mesmos valores da persuasão, consenso e harmonia que asseguram a coesão do todo. Devem ser respeitadas as leis que regem a natureza, lato sensu, e a que a civilização se não opõe - antes se enquadra nela, no seu ritmo, se quer sobreviver, em consonância com a themis. E dessas leis faz parte o poder universal de Afrodite-eros, a que ninguém pode escapar, mas que goza, num contexto civilizado, de códigos próprios.

25 Garvie 2006:204 sqq., enumera e analisa as hipóteses de reconstituição da acção global feita pela investigação e, em particular, da reconstituição possível da parte final de la trilogia. 